
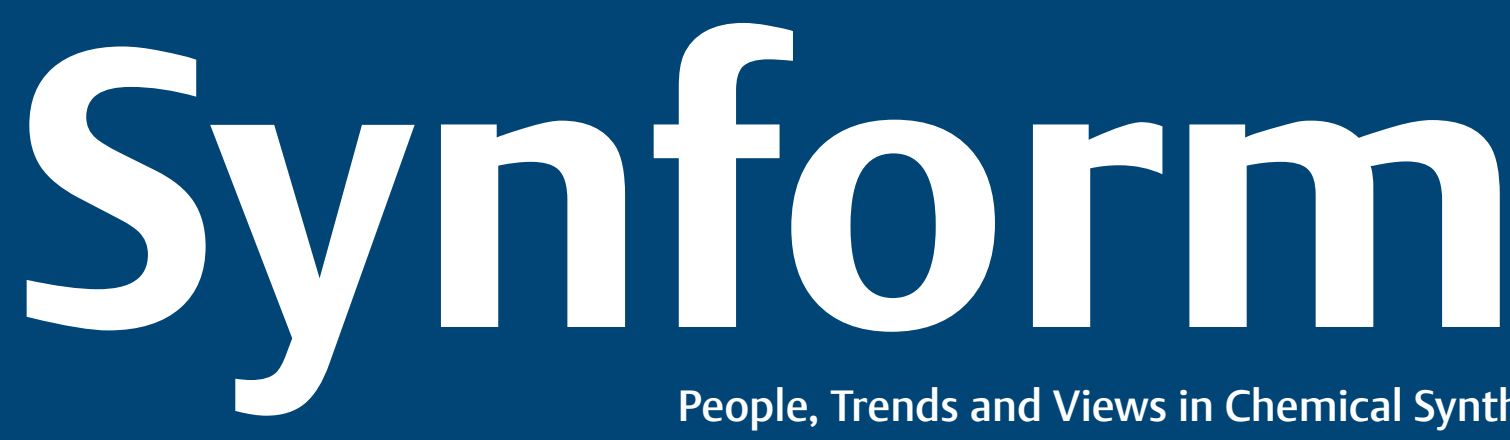

People, Trends and Views in Chemical Synthesis

$$
2019 / 10
$$

\title{
Practical and Regioselective Amination of Arenes Using Alkyl Amines
}

Highlighted article by A. Ruffoni, F. Juliá, T. D. Svejstrup, A. J. McMillan, J. J. Douglas, D. Leonori

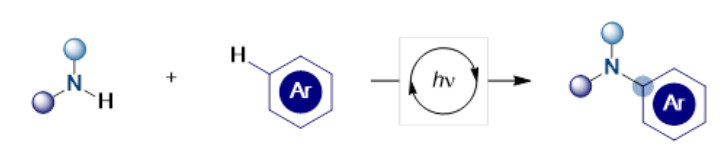
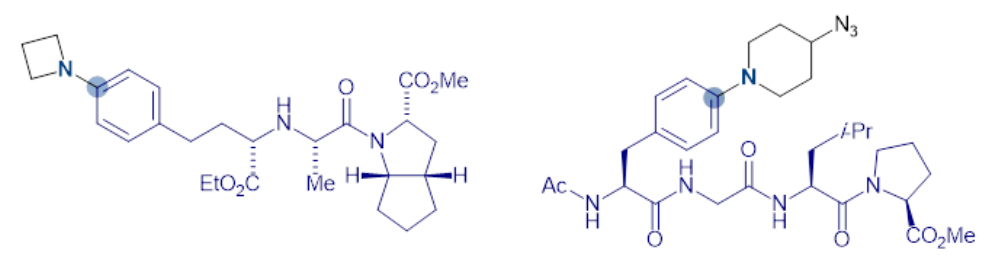

\section{Contact}

Your opinion about Synform is welcome, please correspond if you like:

marketing@thieme-chemistry.com
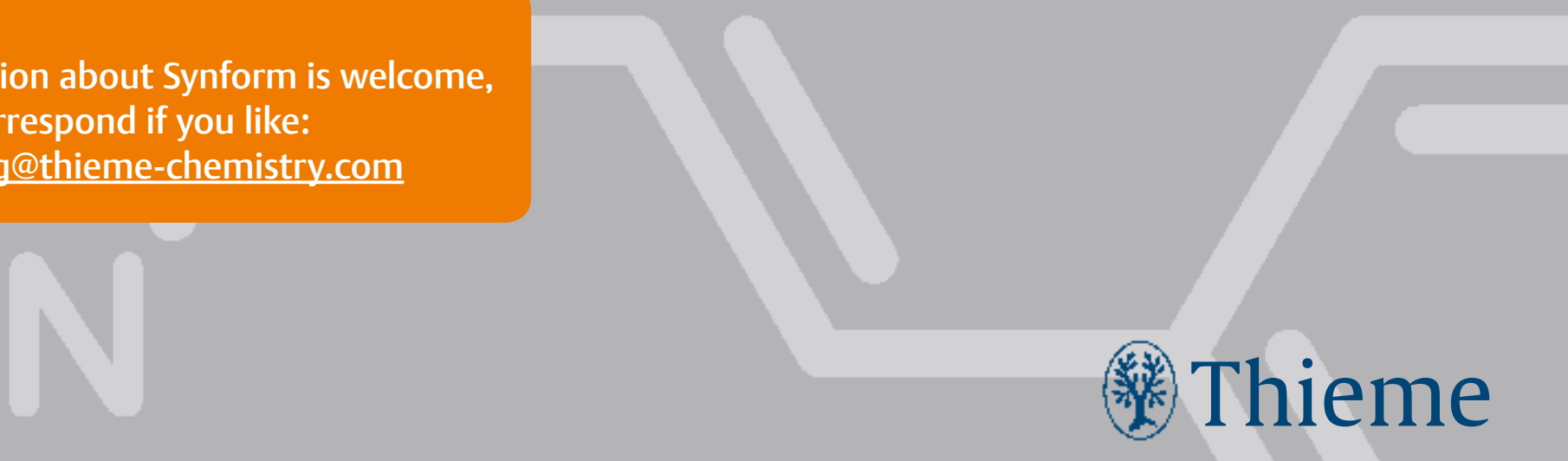


\section{Dear Readers,}

I would like to use this editorial to give you an update and some numbers - on the status of SYNFORM, which - I am delighted to say - is increasingly successful. For the sample six-month period January-June 2019, the clicks on the individual articles hosted on the two websites https://www.thieme.de/en/thiemechemistry/journals-synform-synstories-64292.htm and https://www.thieme.de/en/thieme-chemistry/journalssynform-news-64999.htm were:

- 1,420 average clicks per individual article (article + related SYNFORM News)

- 34,080 clicks in total for the 24 regular SYNFORM articles and the corresponding 24 SYNFORM News

- 5,680 average clicks per month for all articles

On the e-journal platform we recorded an average of 1,250 additional downloads of the monthly SYNFORM issue (PDF version) per month.

These are truly impressive numbers, which demonstrate a massive visibility boost for your original articles featured in each article, as well as for the researchers authoring those papers, including the protagonists of our Young Career Focus interviews.

Clearly, the steady promotion of SYNFORM on social media (such as the very successful Thieme-Chemistry Twitter account), in conferences and in the various e-mail newsletters has contributed to increase considerably the popularity of SYNFORM. These are very exciting times for SYNFORM, and we are extremely grateful for your continued interest and support!!!

Let's now have a look at the articles of this issue, which is opened by a Young Career Focus interview with Rowan D. Young (Singapore), who tells SYNFORM about his research on organic catalysis. Vinod K. Tiwari (India) and his paper in SYNTHESIS on the improved synthesis of ureas via Curtius rearrangement comes

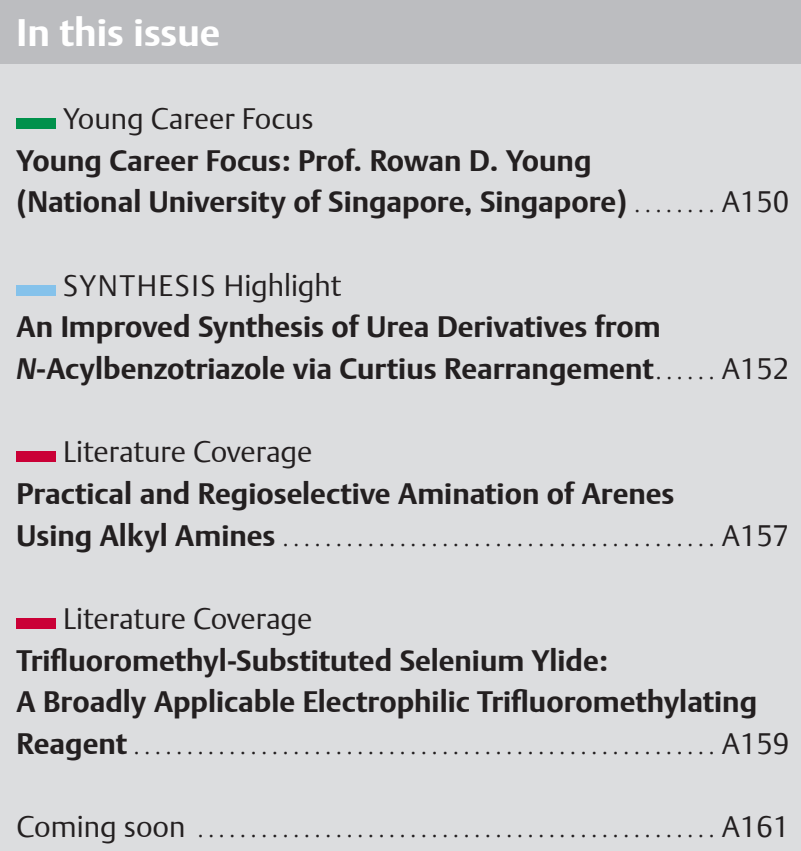

next, followed by Daniele Leonori (UK) and his Nature Chemistry paper on the regioselective amination of arenes using alkyl amines. The wrap-up belongs to Qilong Shen (P. R. of China) and his selenium-based trifluoromethylating reagent.

Enjoy your reading!!!

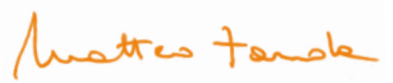

\section{Contact \\ If you have any questions or wish to send feedback, please write to Matteo Zanda at: synform@outlook.com}




\section{Young Career Focus: Prof. Rowan D. Young (National University of Singapore, Singapore)}

Background and Purpose. SYNFORM regularly meets young up-and-coming researchers who are performing exceptionally well in the arena of organic chemistry and related fields of research, in order to introduce them to the readership. This Young Career Focus presents Prof. Rowan D. Young (National University of Singapore, Singapore).

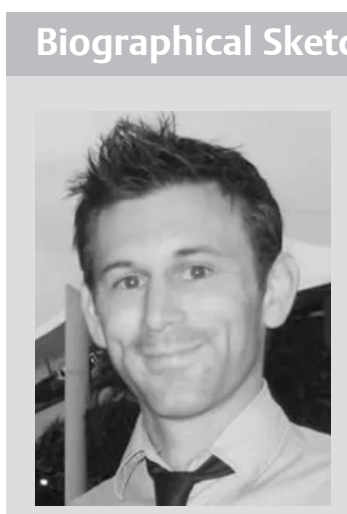

Prof. R. D. Young
Rowan D. Young obtained his BSC (Hons) from the University of New South Wales (Australia). He then went on to pursue his $\mathrm{PhD}$ at the Australian National University under the supervision of Professor Anthony Hill. After stints at Oxford (UK) and Edinburgh (UK) as a postdoctoral researcher with the research groups of Andrew Weller and Polly Arnold, respectively, he took up a position at the National University of Singapore in 2014.

\section{INTERVIEW}

SYNFORM What is the focus of your current research activity?

Prof. R. D. Young My group is concerned with inventing new ways in which to functionalise carbon-fluorine (C-F) bonds. This is primarily achieved using Lewis acid catalysis. Some of the challenges we aim to overcome in this field include enabling C-F activation methods that tolerate a wider range of co-functional groups present in our reaction substrates, improving regio- and chemo-selectivity, and preventing 'over-reaction' of C-F bonds allowing monoselective C-F bond functionalization.

\section{SYNFORM When did you get interested in synthesis?}

Prof. R. D. Young I was trained as an organometallic chemist, concerned with generating new transition-metal catalysts and studying their reaction mechanisms. However, in order to test the activity of any new organometallic catalysts that we generate, it has been necessary to apply such catalysts in organic synthesis. Thus, we have also recently become active as an organic synthesis group.

SYNFORM What do you think about the modern role and prospects of organic synthesis?

Prof. R. D. Young Part of our research concerns the use of waste fluorocarbon materials as starting materials to access various fluorinated targets. There exists huge potential for organic synthesis to employ waste materials as zero-cost or negative-cost starting materials. This offers opportunities for more economical synthetic approaches, and also allows organic syntheses to be 'greener' and offer re-purposing pathways for various waste chemicals. I think that this area of chemical research deserves much more exploration.

SYNFORM Could you tell us more about your group's areas of research and your aims?

Prof. R. D. Young Waste fluorocarbon gases (e.g. hydrofluorocarbons) used in refrigeration and blower applications offer a unique environmental threat as they possess high global warming potentials. Part of our research aims to employ these waste gases as starting materials for the synthesis of partially fluorinated chemicals. To achieve this we need to be able to avoid 'over-reaction' of C-F bonds, and develop methods for monoselective functionalisation. We also aim to increase the variety of functional groups (and possible targets) that can be incorporated into $\mathrm{C}-\mathrm{F}$ positions. 


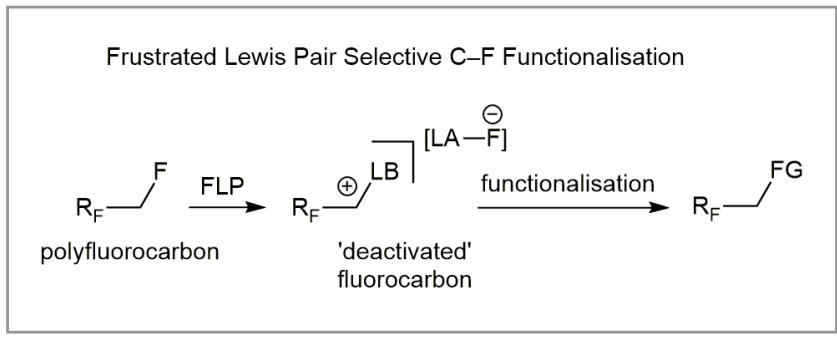

Scheme 1 Aliphatic polyfluorides are prone to 'over-reaction', where more than one $\mathrm{C}-\mathrm{F}$ bond is transformed. Using an FLP approach, we generate cationic intermediates that resist further Lewis acid fluoride abstraction, allowing monoselective $\mathrm{C}-\mathrm{F}$ functionalisation for a range of polyfluorides.

SYNFORM What is your most important scientific achievement to date and why?

Prof. R. D. Young Last year we reported a proof-of-principle for monoselective C-F functionalisation using a Frustrated Lewis Pair (FLP) approach (J. Am. Chem. Soc. 2018, 140, 10682-10686). We hope to further explore this methodology, as in principle, it allows the monoselective activation of any aliphatic polyfluorocarbon, even if the fluoro-positions are distal.

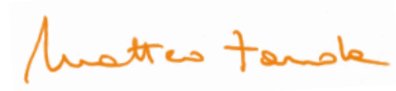




\title{
An Improved Synthesis of Urea Derivatives from $\mathrm{N}$-Acylbenzo- triazole via Curtius Rearrangement
}

\author{
Synthesis 2019, DOI: 10.1055/s-0039-1689937
}

Several molecules incorporating the urea functionality have displayed a vital role in pharmaceutical, analytical, agricultural, polymer science and organic synthesis. ${ }^{1}$ This moiety is found in a number of pharmacologically active molecules, for example carmustine, sorafenib, and many more, thus there is an increasing demand for functionalized ureas to be tested for a variety of applications and biological uses. A traditional and general synthetic method for preparing ureas involves the reaction of amines with phosgene, isocyanates or phosgene derivatives; however, these tend to be considerably toxic. ${ }^{2}$ Ureas can also be obtained via reductive and oxidative carbonylation of amines in the presence of suitable transition-metal catalysts, such as palladium, tungsten, cobalt, copper and nickel. Unfortunately, using carbon monoxide as the source of the carbonyl moiety generally requires harsh conditions, such as high temperature and pressure. ${ }^{3 a}$ Carbon dioxide as a renewable carbon source or $\mathrm{CH}_{3} \mathrm{OH}$ as the $\mathrm{C}-1$ source in the presence of ruthenium pincer complexes has also been used for this purpose; ${ }^{3 b}$ however, the stoichiometric use of expensive dehydrating reagents like di-tert-butyl azodicarboxylate, required to obtain the corresponding isocyanates, again limits the synthetic utility of the procedure. ${ }^{3 c}$ Hofmann and related Curtius, Lossen and Schmidt rearrangements are also wellknown protocols to obtain the related urea derivatives, but all these processes have their drawbacks. Thus, the search for a versatile protocol for the synthesis of urea derivatives under mild reaction conditions remains a challenge for synthetic chemists.

Over the last three decades, the benzotriazole group has been considered as one of the most successful synthetic auxiliaries for a number of reasons. In addition to its nature benzotriazoles are mainly solid, non-toxic, moisture-insensitive, cost-effective, etc. - the triazole scaffold can be easily obtained under standard conditions, is sufficiently stable during the course of many reactions, can be activated for a number of transformations, and finally can be easily removed at the end of the reaction sequence. ${ }^{4} \mathrm{~N}$-Acylbenzotriazoles are considered as an alternative to acid chlorides in $\mathrm{N}-, \mathrm{C}-, \mathrm{O}$ - and $\mathrm{S}$-acylations for the synthesis of amides, esters, acid azides, peptides, oxazolines, diketones, and thiazolines. The group of Dr. Vinod Tiwari at Banaras Hindu University (India) previously devised a method for synthesizing carbamates, thio- carbamates, and symmetric ureas from $\mathrm{N}$-acylbenzotriazoles via Curtius rearrangement, yet this method has limitations, particularly for the synthesis of unsymmetrical ureas. ${ }^{5}$

"Thus, a practical, mild, metal-free, one-pot and highyielding method to synthesize urea derivatives with the aid of $\mathrm{N}$-acylbenzotriazoles as a synthetic auxiliary via generation of $\mathrm{N}$-acylazides was the ultimate goal of our present investigation," said Dr. Tiwari, who added: "We believe that the acyl azide, upon heating, first converted into the corresponding isocyanate intermediate via Curtius rearrangement, which further reacts with amines under mild conditions to afford libraries of symmetric, unsymmetric, $\mathrm{N}$-acyl and cyclic urea derivatives."

Their synthetic strategy begins with the $N$-acylbenzotriazoles 1, prepared from the corresponding carboxylic acids by reaction with thionyl chloride, $\mathrm{NBS} / \mathrm{PPh}_{3}$ or $\mathrm{PySSPy} / \mathrm{PPh}_{3}$ and $1 H$-benzotriazole in dichloromethane. ${ }^{6}$ "Although the reaction of $\mathrm{N}$-acylbenzotriazoles with $\mathrm{NaN}_{3}$ afforded the corresponding carbamates, thiocarbamates, and symmetric ureas in average to good yields via Curtius rearrangement, ${ }^{5}$ the method was not equally applicable for the production of unsymmetrical ureas, which therefore became our next objective, " explained Dr. Tiwari. A number of reactions with a diverse range of reagents were attempted, ending with the conclusion that $\mathrm{N}$-acylbenzotriazole $1 \mathrm{a}$ (1.0 equiv) on treatment with aniline (1.0 equiv), $\mathrm{TMSN}_{3}$ (1.0 equiv) and triethylamine (1.0 equiv) in anhydrous toluene at $110{ }^{\circ} \mathrm{C}$ afforded the required unsymmetrical urea derivative $2 \mathrm{a}$ in $83 \%$ yield. "After achieving this result, conditions were further optimized in terms of reagent and base equivalents, solvent medium, reaction time, and temperature to establish the optimum yield of compound 2a (isolated in 97\% yield) when $\mathrm{N}$-acylbenzotriazole $\mathbf{1 b}$ (1.0 equiv) was heated at $110{ }^{\circ} \mathrm{C}$ with 1.0 equivalent of aniline, 1.1 equivalents of $\mathrm{TMSN}_{3}$ and 2.0 equivalents of triethylamine in anhydrous toluene for 60 minutes," said Dr. Tiwari.

In order to determine the scope of the protocol, a library comprising diverse urea derivatives $\mathbf{2 a - s}$ was developed simply by varying the $\mathrm{N}$-acylbenzotriazole $\mathbf{1}$ and the amine under optimized reaction conditions (Scheme 1 ). "The reaction yield is not entirely dependent on the nature and position of the substituent present on the benzene ring of $\mathrm{N}$-acylbenzotriazoles, or on the nature of amines used," remarked Dr. 


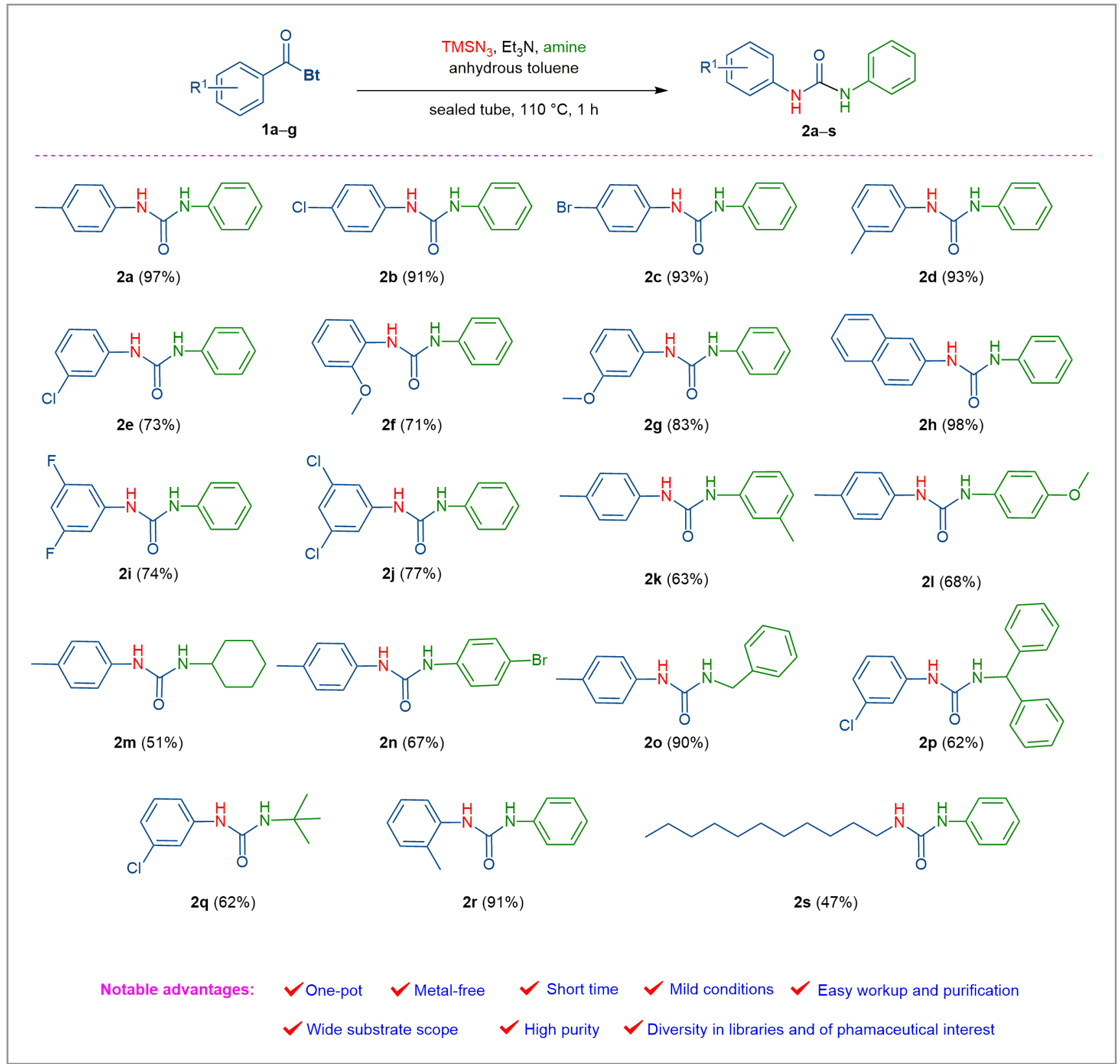

Scheme 1 Synthesis of unsymmetric/symmetric/cyclic and $\mathrm{N}$-acyl urea derivatives 3-6 from $\mathrm{N}$-acylbenzotriazole 2 via Curtis rearrangement using $\mathrm{TMSN}_{3}$. Molar ratios: $\mathrm{N}$-Acylbenzotriazole 1 (1.0 equiv), $\mathrm{TMSN}_{3}$ (1.1 equiv), Et $\mathrm{N}$ (2.0 equiv), aniline derivative (1.0 equiv).

Tiwari. He continued: "A similar reaction of 2a with propargyl amine under optimized conditions resulted in $\mathrm{N}$-(prop-2-yn1 -yl)benzamide as the sole product instead of the respective urea."

To improve further the practical utility of this methodology, the protocol was extended for the synthesis of symme- tric urea 3 and $N$-acylurea derivatives 4 . For the synthesis of symmetric ureas $\mathbf{3 a - f}$ (Scheme 2), aromatic $\mathrm{N}$-acylbenzotriazoles and anilines having the same aromatic rings present on aryl $N$-acylbenzotriazoles were selected under the above optimized conditions. Likewise, 1-(1H-benzo[d][1,2,3]triazol1-yl)-2-phenylethane-1,2-dione (1o) on reaction with aniline 


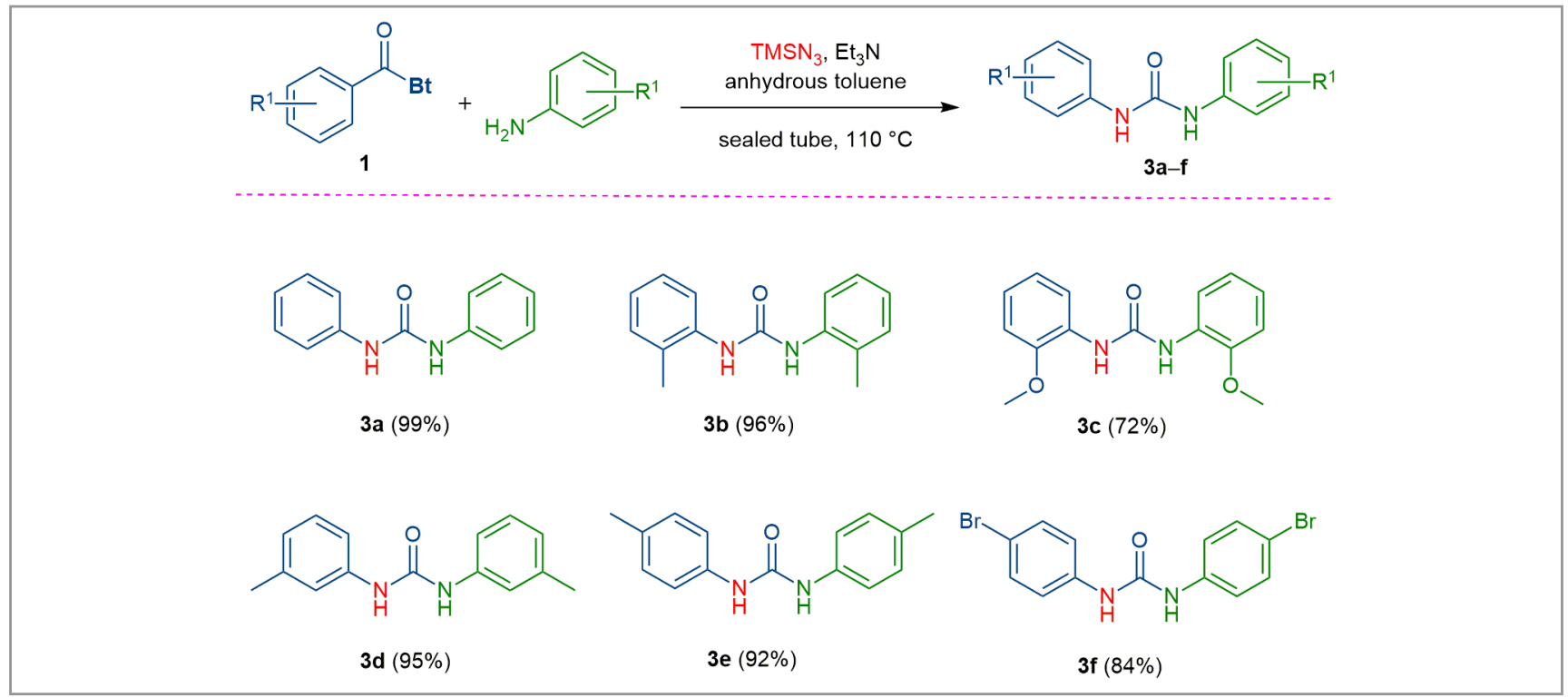

Scheme 2 Symmetric ureas 3a-f from N-acylbenzotriazole 1 via Curtius rearrangement. Molar ratios: $N$-Acylbenzotriazole 1 (1.0 equiv), $\mathrm{TMSN}_{3}$ (1.1 equiv), $\mathrm{Et}_{3} \mathrm{~N}$ (2.0 equiv), aniline derivative ( 1.0 equiv).

under the optimum reaction conditions afforded $\mathrm{N}$-acyl ureas 4a-c in satisfactory yields (Scheme 3 ).

Finally, the authors successfully exploited the protocol in order to obtain cyclic ureas simply by reacting $\mathrm{N}$-acylbenzotriazoles 1m,n under optimized conditions, affording cyclic ureas $\mathbf{5 a , b}$ in excellent yields via intramolecular cyclization through isocyanate intermediates (Scheme 4). "A plausible mechanism to explain the formation of ureas 2-5 involves an acyl azide intermediate formed by the nucleophilic addition of an azide ion to the carbonyl carbon of acyl benzotriazole through the displacement of benzotriazole as leaving group," explained Dr. Tiwari. He continued: "The acyl azide intermediate further undergoes Curtius rearrangement to afford the isocyanate intermediate with the subsequent loss of molecular nitrogen, finally captured by an amine to produce the final urea derivatives."

Dr. Tiwari concluded: "The key step of this new method relies on the good leaving group nature of the benzotriazole moiety, which was exploited for the synthesis of a number of different ureas. In many cases, column chromatography was avoided and thus, the devised protocol can certainly be considered for its practical use in both academia and industry."<smiles>[R]c1ccc(NC(=O)NC(=O)c2ccccc2)cc1</smiles>

Scheme $3 \mathrm{~N}$-Acylureas 4a-c from 1-(1H-benzo[d][1,2,3]triazol-1-yl)-2-phenylethane-1,2-dione (10). Molar ratios: N-Acylbenzotriazole 1 (1.0 equiv), TMSN $_{3}$ (1.1 equiv), Et $\mathrm{N}$ (2.0 equiv), aniline derivative (1.0 equiv). 


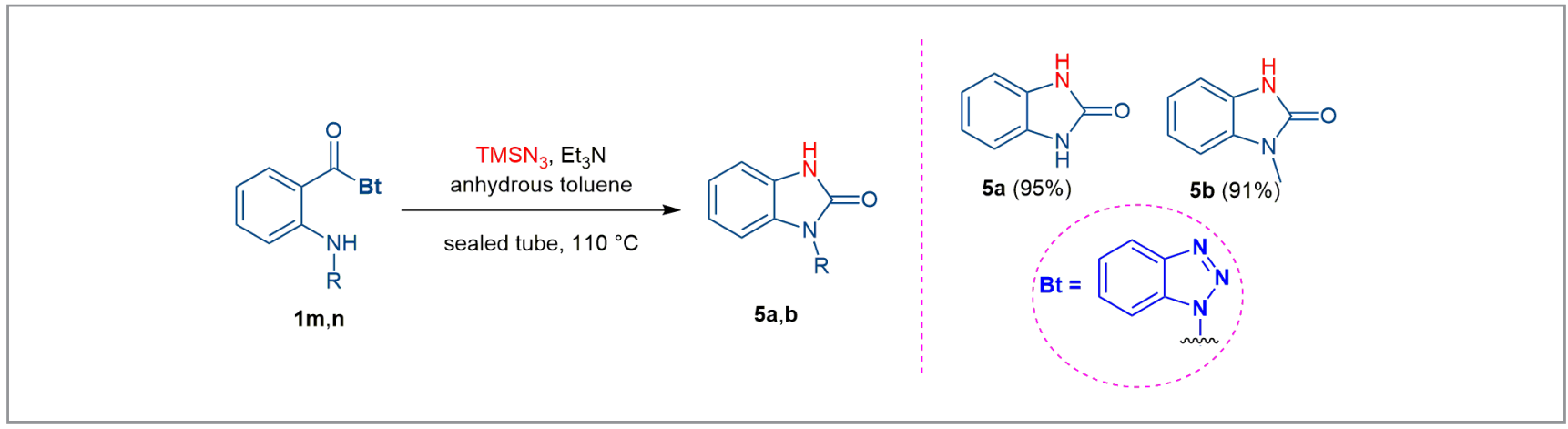

Scheme 4 Cyclic urea derivatives 5a,b from $\mathrm{N}$-acylbenzotriazoles $\mathbf{1}$ m, n via Curtius rearrangement. Molar ratios: $\mathrm{N}$-Acylbenzotriazole 1 (1.0 equiv), TMSN $_{3}$ (1.1 equiv), $\mathrm{Et}_{3} \mathrm{~N}$ (2.0 equiv), aniline derivative (1.0 equiv).

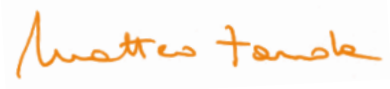

\section{REFERENCES}

(1) T. W. von Geldern, C. Hutchins, J. A. Kester, J. R. Wu-Wong, W. Chiou, D. B. Dixon, T. J. Opgenorth J. Med. Chem. 1996, 39, 957-967.

(2) H. Babad, A. G. Zeiler Chem. Rev. 1973, 73, 75-91.

(3) (a) Z.-H. Guan, H. Lei, M. Chen, Z.-H. Ren, Y. Bai, Y.-Y. Wang Adv. Synth. Catal. 2012, 354, 489-496. (b) S. H. Kim,

S. H. Hong Org. Lett. 2016, 18, 212-215. (c) S. L. Peterson,

S. M. Stucka, C. J. Dinsmore Org. Lett. 2010, 12, 1340-1343.

(4) A. R. Katritzky, X. Lan, J. Z. Yang, O. V. Denisko Chem. Rev. 1998, 98, 409-548.

(5) A. S. Singh, D. Kumar, N. Mishra, V. K. Tiwari RSC Adv. 2016, 6, 84512-84522.

(6) (a) A. S. Singh, M. Singh, A. K. Agrahari, N. Mishra, V. K. Tiwari Synthesis 2019, 51, 470-476. (b) M. Singh, A. S. Singh, N. Mishra, A. K. Agrahari, V. K. Tiwari Synthesis 2019, 51, 2183-2190.

(7) A. K. Singh, A. K. Agrahari, S. K. Singh, M. S. Yadav, V. K. Tiwari Synthesis 2019, 51, DOI: 10.1055/s-00391689937. 


\section{About the authors}

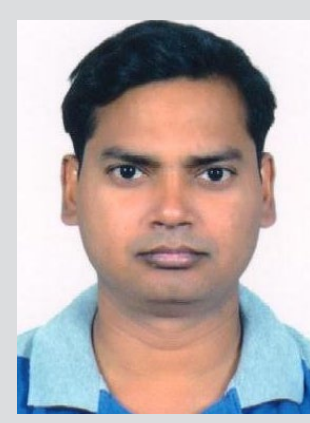

Dr. A. S. Singh
Anoop S. Singh was born in Varanasi, Uttar Pradesh (India) in 1986. He obtained his M.Sc. degree in chemistry (2010, specializing in organic chemistry) from U.P. College, Varanasi (India) and qualified Common Entrance Test (CET, 2012), Graduate Aptitude Test in Engineering (GATE2013), and National Eligibility TestLectureship (NET, 2013). Recently, in 2018 he completed his PhD degree from the Department of Chemistry at Banaras Hindu University (BHU, India) under the guidance of Dr. V. K. Tiwari with his thesis on the development of novel synthetic methodology through benzotriazole ring cleavage (BtRC). Dr. Anoop Singh has contributed significantly to about 18 publications.

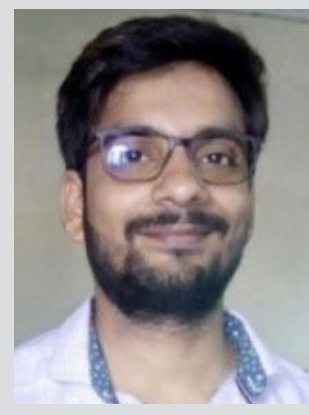

A. K. Agrahari

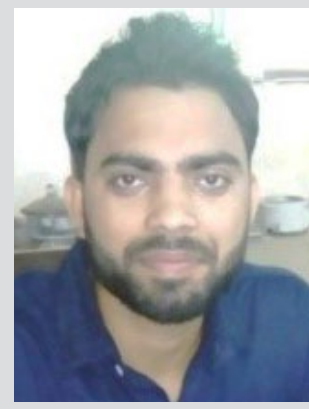

S. K. Singh
Anand K. Agrahari was born in Chandauli, Uttar Pradesh, India, in 1993. He obtained his B.Sc. (2013) and M.Sc. degrees in chemistry (2015) from Banaras Hindu University, India. After qualifying as a Junior Research Fellow (JRF) from CSIR-UGC, he joined Dr. V. K. Tiwari's lab for doctoral work on click-inspired synthesis of glycodendrimers and their applications.

Sumit K. Singh was born in Jaunpur, India, in 1993. He obtained his M.Sc. (2017, specializing in organic chemistry) from Banaras Hindu University, India. After obtaining a Junior Research Fellowship (JRF) from the CSIR-UGC-NET in 2017, he joined the research group of Dr. V. K. Tiwari at $\mathrm{BHU}$ for his Ph.D. degree, where his topic of interest focuses on the development of novel glycoconjugates and their application in catalysis.

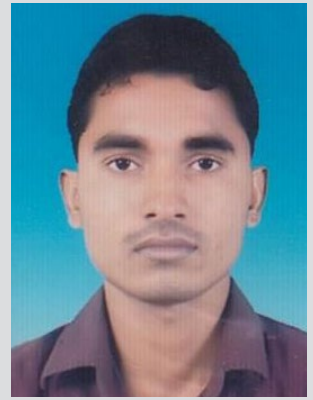

Mangal S. Yadav was born in Azamgarh, Uttar Pradesh, India in 1992 and is currently working as a Ph.D. student in the Department of Chemistry, Banaras Hindu University, India under the supervision of Dr. V. K. Tiwari. He obtained his Master's degree in chemistry in 2013 from V.B.S. Purvanchal University, Jaunpur (India) and then qualified GATE (2017) and M. S. Yadav NET (2017) as CSIR-JRF. His research interest focuses on benzotriazole methodology and applications.

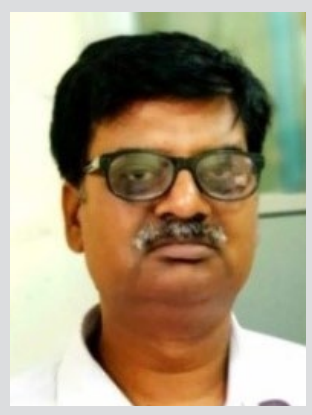

Vinod K. Tiwari is associated with Banaras Hindu University (BHU), India since 2005 where he is an associate professor of organic chemistry. After completing his MSc from BHU in 1998, he qualified CSIR-UGC-NET, GATE, SET, and then began his doctoral research at CSIR-Central Drug Research Institute, Lucknow, India followed by postdoctoral experience at the University of Florida (USA), the University of California-Davis (USA),

Dr. V. K. Tiwari and Universitat Konstanz (Germany). He was offered the post of
Lecturer at Bundelkhand University, Jhansi, India (2004-2005) before being appointed to his current post at BHU. With more than 20 years of research and 15 years of teaching experience, Dr. Tiwari has supervised $11 \mathrm{PhD}$ theses and contributed significantly to 130 peer-reviewed publications, several patents and invited book chapters. His research has been recognized with many prestigious honors, awarded by Indian Chemical Society, Chemical Research Society of India, Indian Science Congress Association, Indian Council of Chemists, and more. His current research focuses on various aspects of carbohydrate chemistry and the development of novel synthetic methodologies. 


\section{Practical and Regioselective Amination of Arenes Using Alkyl Amines}

Nat. Chem. 2019, 11, 426-433

Anilines are organic molecules made of an aromatic and an amine component linked through a carbon-nitrogen bond. The formation of these bonds is among the top five reactions carried out globally and it is used to prepare widely prescribed medicines, agrochemicals and materials. In general, these high-value molecules are assembled using multi-step sequences where the aromatic component is pre-functionalized to enable the formation of the $\mathrm{C}-\mathrm{N}$ bond.

Photoredox catalysis can offer new and more environmentally sustainable solutions to the problem of synthesizing complex organic compounds - including N,N-disubstituted anilines - simply by harnessing the energy of light for promoting chemical reactions in the presence of a light-sensitive catalyst that can mediate electron transfers between readily available starting materials.

In this recent paper, the group of Dr. Daniele Leonori at the University of Manchester (UK) has developed a new chemical method that assembles anilines by direct reaction of aromatic and alkyl amines upon blue light irradiation (Scheme 1). Dr. Leonori said: "This streamlined process offers an improved and cost-effective strategy for the preparation and modification of complex and densely functionalized materials."

Through a collaboration with the pharmaceutical company AstraZeneca, the group has applied this new reaction to the modification of drugs, agrochemicals, peptides, chiral catalysts, polymers and organometallic complexes, and has demonstrated its scalability by flow technologies.

Dr. Leonori concluded: "We hope that this methodology will be perceived as a viable alternative to classical crosscoupling approaches and will be of use to researchers active in the area."

Professor David A. Nicewicz, an expert in photoredox catalysis from the University of North Carolina (Chapel Hill, USA) and an Editorial Board Member of SYNLETT, commented "This is a simple and elegant solution to the coupling of second amines and arenes and will likely find widespread use in pharmaceutical and agrochemical discovery programs."

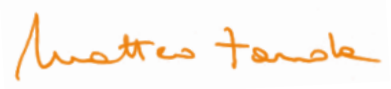

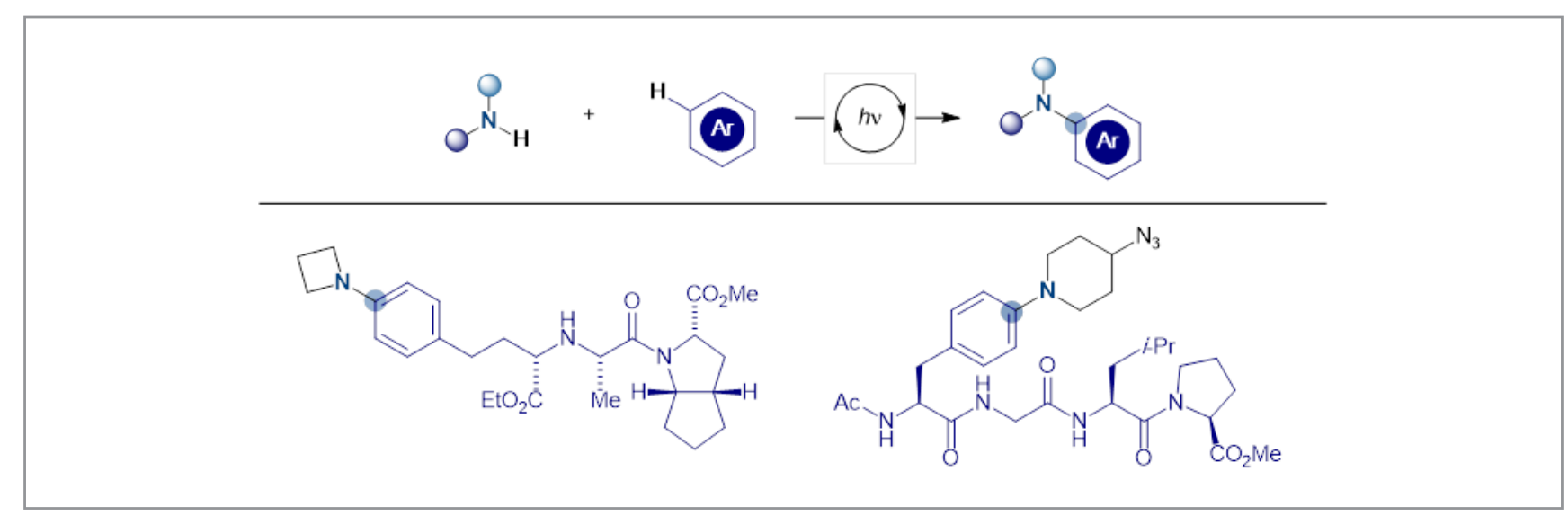

Scheme 1 Photoredox catalysis enables the direct and selective coupling of unfunctionalized amines and aromatics. The methodology can be used for the late-stage modification of bio-active materials, small peptides and organometallic complexes. 


\section{About the authors}

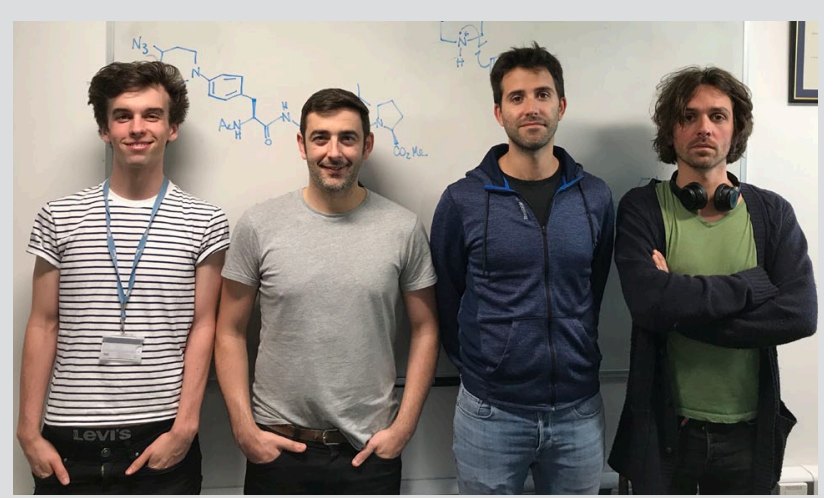

From left to right: A. J. McMillan, F. Juliá, D. Leonori and A. Ruffoni

Daniele Leonori (second from right) obtained his PhD in organic chemistry at the University of Sheffield (UK) under the supervision of Prof. lain Coldham. After postdoctoral stays with Prof. Magnus Rueping and Prof. Peter Seeberger, he joined the group of Prof. Varinder Aggarwal FRS as research officer. Daniele started his independent career at the University of Manchester (UK) in 2014 and was promoted to Reader in 2018. He is the recipient of an EPSRC Early Career Fellowship, the ERC Starter Grant and the 2018 RSC Harrison-Meldola Memorial Prize.

Alessandro Ruffoni (right) studied medicinal chemistry at the Univerisita' di Milano Statale (Italy) and obtained his PhD at the same institution under the supervision of Prof. Francesca Clerici. Following a research stay in the group of Prof. Phil Baran (Scripps, USA), he moved to IRB Barcelona (Spain) under the supervision of Prof. Anthony Riera and Prof. Xavier Salvatella working on ID proteins. In 2016 he was awarded a Marie Curie Fellowship and joined Dr. Leonori's research group.
Fabio Juliá (second from left) obtained his MChem and PhD in inorganic chemistry at the University of Murcia (Spain) under the supervision of Prof. Gonzalez-Herreros for which he was awarded the prize for best PhD thesis in photochemistry by the Spanish Royal Society. Following a research stay in the group of Prof. Corey Stephenson (University of Michigan, USA), he joined Dr. Daniele Leonori's research group in 2017 as a postdoctoral research fellow.

Alastair J. McMillan (left) studied MChem with industrial experience at the University of Manchester (UK) with a year placement at AstraZeneca (Macclesfield, UK). In 2017 he started his $\mathrm{PhD}$ at the same institution under the supervision of Dr. Daniele Leonori.

James J. Douglas (not pictured) studied chemistry at the University of York (UK) and obtained his PhD from the University of St. Andrews (UK) under the supervision of Prof. Andy Smith. Following an Eli Lilly sponsored LIFA Industrial postdoctoral position under the supervision of Prof. Corey Stephenson (University of Michigan, USA), James joined AstraZeneca (Macclesfield, UK) where he is now Associate Principal Scientist. He is the recipient of the 2018 AstraZeneca IMED Scientist of the Year Award.

Thomas D. Svejstrup (not pictured) studied chemistry at the University of Bristol (UK) and then moved to Manchester (UK) to work under the supervision of Dr. Daniele Leonori for his $\mathrm{PhD}$. Since 2018 he has been a postdoctoral research associate at AstraZeneca in Gothenburg (Germany). 


\title{
Trifluoromethyl-Substituted Selenium Ylide: A Broadly Applicable Electrophilic Trifluoromethylating Reagent
}

\author{
Org. Chem. Front. 2019, 6, 2205-2209
}

Many electrophilic trifluoromethylating reagents have emerged in the past three decades. Among them, Umemoto's reagent and Togni's reagent are two of the most studied electrophilic trifluoromethylating reagents due to their high reactivity and broad substrate scope. Nevertheless, new, highly reactive and easily prepared electrophilic trifluoromethylating reagents are still urgently needed.

Recently, the group of Professor Qilong Shen at the Shanghai Institute of Organic Chemistry, Chinese Academy of Sciences (P. R. of China) discovered that monofluoromethyl- or difluoromethyl-substituted sulfonium ylides, which could be synthesized from 4-nitrophenylthiol in two steps, were highly active and reacted with a broad range of nucleophiles under mild conditions. ${ }^{1,2}$ However, the reactivity of the corresponding trifluoromethyl-substituted sulfonium ylide was only moderate. "It is generally accepted that the bond strength of carbon-selenium bonds is weaker than that of carbon-sulfur bonds. We thus reasoned that a trifluoromethyl-substituted selenium ylide might act as a more powerful electrophilic trifluoromethylating reagent," explained Professor Shen. He continued: "We then successfully developed a procedure that led to the synthesis of the trifluoromethyl-substituted selenium ylide 1 from 4-nitrophenyl diazonium salt in two steps (Scheme 1)."

As expected, this compound was indeed a powerful electrophilic trifluoromethylating reagent, which could react with a variety of nucleophiles including $\beta$-keto esters, silyl enol ethers and aryl/heteroaryl boronic acids (Scheme 2). In addition, irradiation of $\mathbf{1}$ with visible light easily generated the trifluoromethyl radical, which reacted readily with electronrich heteroarenes and sulfonates in high yields. Finally, it was found that diarylselenide was a major side product that could be reused to synthesize the reagent. Professor Shen remarked: "Overall, its ease of preparation, convenience in purification, and high thermal stability in the solid state yet high reactivity in solution made the trifluoromethyl-substituted selenium ylide 1 a magic wand for incorporation of the trifluoromethyl group into the target molecules."

Professor Shen went on to summarize five key points of the group's findings: "First, the time for preparing the reagent $\mathbf{1}$ is short, about one hour. Second, the purification by recrystallization is convenient and there is no need for column chromatography. Third, 1 has very good thermal stability in the solid state; it is not moisture-, air- or light-sensitive either. Fourth, it requires only mild reaction conditions. Finally, latestage modification is possible."

Professor Shen concluded by mentioning some future prospects: "Very recently, we discovered that in the presence of a photoredox catalyst, trifluoromethylative difunctionalization of styrene derivatives using the reagent occurred with a broad substrate scope and in high yields. Our lab is currently investigating this process."

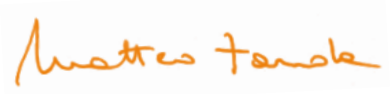

\section{REFERENCES}

(1) Y. Liu, L. Lu, Q. Shen Angew. Chem. Int. Ed. 2017, 56, 9930-9934.

(2) J. Zhu, Y. Liu, Q. Shen Angew. Chem. Int. Ed. 2016, 55, 9050-9054.

(3) Y. Liu, X. Shao, P. Zhang, L. Lu, Q. Shen Org. Lett. 2015, 17 , 2752-2755.

Scheme 1 Preparation of the reagent 
<smiles>[R]CC1(C([R])[R])C(=O)c2ccc([R])cc21</smiles><smiles>[R]O[R]O[Na]</smiles><smiles>[R1]C=C([R])O[Na]</smiles>

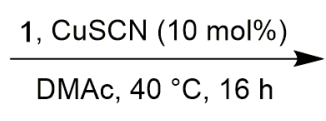<smiles>[R]C(=O)C([R])C(F)(F)F</smiles><smiles>Oc1ccccc1</smiles>

\section{$1, \mathrm{CuCl}$ (1.2 equiv)} $\underset{\text { DMF, rt, } 16 \mathrm{~h}}{\stackrel{\mathrm{Cs}_{2} \mathrm{CO}_{3}(0.8 \text { equiv })}{\longrightarrow}}$<smiles>FC(F)(F)c1ccccc1</smiles><smiles>c1ccc2[nH]ccc2c1</smiles>

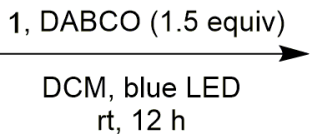<smiles>FC(F)(F)c1cc2ccccc2[nH]1</smiles><smiles>[R]c1ccc(S(=O)(=O)[O-])cc1</smiles>

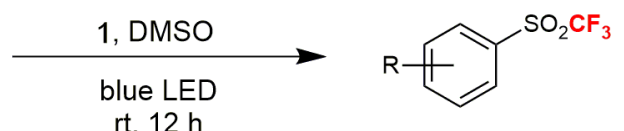

Scheme 2 Trifluoromethylation reactions performed with the new reagent

\section{About the authors}

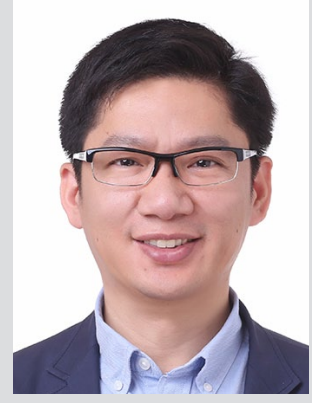

Prof. Q. Shen
Qilong Shen was born in 1974, in Zhejiang (P. R. of China). He studied for his Bachelor's degree from 19921996 in Nanjing University (P. R. of China) and his MS from 1996-1999 at the Shanghai Institute of Organic Chemistry, Chinese Academy of Sciences (P. R. of China) with Prof. Long Lu. He remained there for one more year as a research assistant, still with Prof. Long Lu, before moving to the USA in 2000 to complete another MS degree at the University of Massachusetts at Dartmouth (USA) under Prof. Gerald B. Hammond. From 2002-2007, he undertook his PhD studies at the Department of Chemistry, Yale University (USA) with Prof. John F. Hartwig before moving to the University of Illinois, Urbana-Champaign (USA) as a postdoctoral researcher with Prof. Jeffrey S. Moore. He remained there until 2010, when he moved to his present position as a professor at the Shanghai Institute of Organic Chemistry, Chinese Academy of Science.

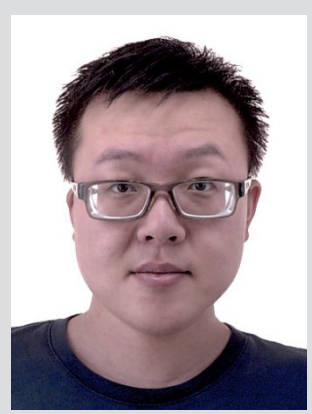

Hangming Ge was born in 1993 in Liaoning (P. R. of China). He studied for his Bachelor's degree in 20112015 at East China Normal University with Prof. Qiancai Liu, where his research was centered on the synthesis of fluoranthene-fused thiophene and pyrrole, and palladium-catalyzed Suzuki coupling towards 1,8-naphthyridines. Since 2015 he has been a PhD candidate at the Shanghai Institute of Organic Chemistry, Chinese
Academy of Sciences under Prof. Qilong Shen. His research foH. Ge cuses on the synthesis and applications of electrophilic reagents for trifluoromethylation based on selenium ylides. 


\section{Coming soon}

\section{- Literature Coverage}

Enantioselective Synthesis of cis-Hydrobenzofurans Bearing

All-Carbon Quaternary Stereocenters and Application to

Total Synthesis of (-)-Morphine

\section{- Literature Coverage}

\section{Sulfonyl Fluoride Synthesis through Electrochemical \\ Oxidative Coupling of Thiols and Potassium Fluoride}

- Conference Report

Report on the 2019 Thieme Chemistry Editorial Board

Meeting

\section{Further highlights}

Synthesis Review: Recent Advances towards Syntheses of Diterpenoid Alkaloids

(by M. Lautens and co-workers)

Synlett Account: Nitrosoalkenes: Underappreciated Reactive Intermediates for Formation of Carbon-Carbon Bonds (by S. M. Weinreb)

Synfacts Synfact of the Month in category "Synthesis of Materials and Unnatural Products": Synthesis of Conjugated Nanohoops Containing Antiaromatic Units
Editor

Matteo Zanda, Chair in Biomolecular Imaging, Centre for Imaging Science, Department of Chemistry, School of Science, Loughborough University, Leicestershire, LE11 3TU, UK and

C.N.R. - Istituto di Chimica del Riconoscimento Molecolare

Via Mancinelli, 7, 20131 Milano, Italy

Editorial Assistant: Alison M. Sage

synform@outlook.com; fax: +39 0223993080

Editorial Office

Managing Editor: Susanne Haak,

susanne.haak@thieme.de, phone: +497118931786

Scientific Editors:

Stefanie Baumann, stefanie.baumann@thieme.de, phone: +49 7118931776 Selena Boothroyd, selena.boothroyd@thieme.de

Michael Binanzer, michael.binanzer@thieme.de, phone: +49 7118931768

Giuliana Rubulotta, giuliana.rubulotta@thieme.de, phone: +49 7118931183

Kathrin Ulbrich, kathrin.ulbrich@thieme.de, phone: +49 7118931785

Senior Production Editors:

Thomas Loop, thomas.loop@thieme.de, phone: +49 7118931778

Thorsten Schön, thorsten.schoen@thieme.de, phone: +49 7118931781

- Production Manager: Sophia Hengst,

sophia.hengst@thieme.de, phone: +497118931398

- Production Assistant: Tobias Brenner

Tobias.brenner@thieme.de, phone: +49711 8931769

Editorial Assistant: Sabine Heller,

sabine.heller@thieme.de, phone: +49 7118931744

Marketing Director: Julia Stötzner

julia.stoetzner@thieme.de, phone: +497118931771

Postal Address: Chemistry Journals, Editorial Office, Georg Thieme Verlag KG,

Rüdigerstraße 14, 70469 Stuttgart, Germany,

Homepage: www.thieme-chemistry.com

Publication Information

Synform will be published 12 times in 2019 by Georg Thieme Verlag KG, Rüdigerstraße 14, 70469 Stuttgart, Germany, and is an additional online service for Synthesis, Synlett and Synfacts.

Publication Policy

Product names which are in fact registered trademarks may not have been specifically designated as such in every case. Thus, in those cases where a product has been referre to by its registered trademark it cannot be concluded that the name used is public

domain. The same applies as regards patents or registered designs.

Ordering Information for Print Subscriptions to Synthesis, Synlett and Synfacts The Americas: Thieme Publishers New York, Thieme Medical Publishers, Inc., 333 Seven Avenue, New York, NY 10001, USA.

Via e-mail: customerservice@thieme.com

Via website: www thieme-chemistry com

Phone: +1 212760 0888; Fax: +1 2129471112

Order toll-free within the USA: +1 8007823488

Europe, Africa, Asia, and Australia: Thieme Publishers Stuttgart, Georg Thieme Verlag KC, Rüdigerstraße 14, 70469 Stuttgart, Germany.

Via e-mail: customerservice@thieme.de

Via website: www.thieme-chemistry.com

Phone: +49 7118931 421; Fax: +49 7118931410

Current list prices are available through www.thieme-chemistry.com.

Online Access

The online versions of Synform as well Synthesis, Synlett, Synfacts and SynOpen are available through www thiemeconnect.com/products/ejournals/journals) where it is also possible to register for a free trial account. For information on multi-site licenses and pricing for corporate customers as well as backfiles, please contact our regional offices: The Americas: esales@thieme.com, phone: +1 2125844695

Europe, Africa, Asia, and Australia: eproducts@thieme.de, phone: +49 7118931407 India: eproducts@thieme.in, phone +911204556600 Japan: brhosoya@poplar.ocn.ne.jp, phone+8133358 0692

Manuscript Submission to Synthesis, Synlett, and SynOpen Manuscript submissions will be processed exclusively online via

http://mc.manuscriptcentral.com/synthesis, http://mc.manuscriptcentral.com/synlett and http://mc.manuscriptcentral.com/synopen, respectively. Please consult the Instructions for Authors before compiling a new manuscript. The current version and the Word template for manuscript preparation are available for download at www.thieme-chemistry.com.

Copyright

This publication, including all individual contributions and illustrations published therein is legally protected by copyright for the duration of the copyright period. Any use, exploitation or commercialization outside the narrow limits set by copyright legislation, without the publisher's consent, is illegal and liable to criminal prosecution. This applies to translating, copying and reproduction in printed or electronic media forms (databases, online network systems, Internet, broadcasting, telecasting, CD-ROM, hard disk storage, microcopy edition, photomechanical and other reproduction methods) as well as making the material accessible to users of such media (e.g., as online or offline backfiles).

Copyright Permission for Users in the USA

Authorization to photocopy items for internal or personal use, or the internal or persona use of specific clients, is granted by Georg Thieme Verlag KG Stuttgart. New York for libraries and other users registered with the Copyright Clearance Center (CCC) Transactional Reporting Service, provided that the base fee of US $\$ 25.00$ per copy of each article is paid directly to CCC, 22 Rosewood Drive, Danvers, MA 01923, USA, 0341-0501/02.
SYNFORM issue 2019/11 is available from October 18, 2019

at www.thieme-connect.com/ejournals 